\title{
Entrevista e Descoberta de Processos em Ambientes Desafiadores: uma releitura econômico-comportamental inspirada no MINDSPACE
}

\section{Interviews and Process Discovery in Challenging Environments: a behavioral- economics approach inspired by MINDSPACE}

\author{
Luiz Flávio Arreguy Maia-Filho ${ }^{1}$, Marco Aurélio Benevides de Pinho \\ ${ }^{1}$ Departamento de Economia, Universidade Federal Rural de Pernambuco, Recife, Brasil \\ ${ }^{2}$ Departamento de Administração, Universidade Federal Rural de Pernambuco, Recife, Brasil \\ Correspondência: Luiz Flávio Arreguy Maia-Filho, Universidade Federal Rural de Pernambuco, Endereço: Rua \\ Dom Manuel de Medeiros, s/n, Dois Irmãos, CEP.: 52171-900 Recife, Brasil. Tel: +55 (81) 9-9112-3884. e-mail: \\ luiz.maia@ufrpe.br
}

Recebido: 5 de outubro de 2018 Aceito: 30 de novembro de 2018 Publicado: 31 de dezembro de 2018

DOI: http://dx.doi.org/10.21714/1679-18272018v16Ed.p293-306

\begin{abstract}
Resumo
O artigo propõe a incorporação de elementos econômico-comportamentais do arcabouço MINDSPACE à etapa de descoberta de processos de negócios em organizações complexas, sobretudo em ambientes marcados pelo desengajamento e a participação relutante das equipes. O planejamento - via fluxograma BPMN - e a execução das entrevistas com gestores e atores envolvidos ganham novos contornos com a incorporação de atividades capazes de mitigar riscos e aproveitar oportunidades de transformação organizacional; busca-se favorecer a livre expressão e a postura plenamente colaborativa. Desde o devido destaque à importância das diferentes perspectivas, passando pela firmeza nos compromissos acordados e pela previsão de canais para a submissão de informações possivelmente sensíveis, até a expressa manifestação de respeito em relação aspectos afetivos e de autoimagem na conduta profissional: todos são considerados aspectos fundamentais de uma rica interação humana que, se devidamente compreendida como aprendizagem organizacional, não deveria ocorrer apenas ocasionalmente, quando na fortuita presença de perfis mais qualificados de liderança.
\end{abstract}

Palavras-chave: Gestão de Processos, BPM, Descoberta, Economia Comportamental, MINDSPACE

\begin{abstract}
The paper incorporates aspects of the MINDSPACE behavioral framework into business process discovery at complex organizations, particularly in disengaging and reluctance-driven environments. Planning - via BPMN workflows - and carrying out specific activities in process-discovery interviews can, in principle, mitigate risks and seize opportunities to strengthen collaboration and promote free expression. From the due recognition of all individuals' frames (viewpoints), through the trustworthiness of commitments, the availability of special channels for sensitive information, to the explicit manifestation of respect for affect-based professional atitudes and identities: all are fundamental elements of a rich human-interaction experience that, once considered indispensable for organizational learning, should not occur only fortuitously, whenever the most qualified leadership is directly involved.
\end{abstract}

Keywords: Business Process Management, BPM, Discovery, Behavioral Economics, MINDSPACE.

Esta obra está licenciada sob uma Licença Creative Commons Attribution 3.0.

\section{Introdução}

O presente artigo propõe uma releitura econômico-comportamental para momento crítico nas etapas de descoberta e mapeamento de processos de negócios, sobretudo no contexto de organizações de alta complexidade, como as 
http://www.revista.ufpe.br/gestaoorg

universidades públicas brasileiras: a realização de entrevistas semiestruturadas com gestores e atores, que antecede e subsidia a elaboração de modelos diagnósticos. Busca-se, aqui, identificar, articular e modelar formalmente aquelas que tendem a ser intuitivamente consideradas boas práticas, consolidando-as em um fluxograma na notação BPMN (Business Process Modeling Notation), de modo a favorecer a mais efetiva colaboração possível. A proposta se destina, em particular, a subsidiar a busca por precisão no diagnóstico organizacional em ambientes suscetíveis ao desengajamento, possivelmente revelado pelos entrevistados através de comportamentos como: (i) participação irregular ou irrefletida em reuniões; (ii) grau reduzido de criticidade (ou autocrítica) ética; (iii) relutância à autoexposição no momento de opinar sobre eventuais riscos e oportunidades de mudança; e/ou (iv) na subestimação de previsíveis consequências da estagnação organizacional (BANDURA, 1991; PEREIRA, 1996; DETERT et al., 2008).

Sob tal perspectiva, admite-se que o planejamento formal e a execução de uma entrevista para a descoberta de(s) processo(s) de forma atenta a aspectos comportamentais podem, a princípio, lhe conferir novos significados, equilibrar parte dos incentivos envolvidos e, assim, favorecer a reflexão e a livre expressão colaborativa. Tal proposta dialoga e se alia a um conjunto de esforços consolidados e ampliados por Eikebrokk et al. (2011): ao mostrarem como a aceitação e o uso da modelagem de processos são tipicamente patrocinados pela alta administração, mas claramente influenciados por fatores pessoais e sociopolíticos nas organizações, os autores estabeleceram as bases para novas articulações entre a literatura BPM e a pesquisa econômico-comportamental que investiga os impactos de influências e contextos na cognição e no comportamento (SAMSON, 2015). Na mesma linha, conjectura-se que a convergência dessas agendas de pesquisas pode também contribuir com os estudos sobre a gestão de pessoas em ambientes de trabalho crescentemente marcados pela hiperconectividade (FREDETTE et al., 2012) e pela Shadow I.T. (SILIC; BACK, 2014).

\section{Referencial Teórico}

\subsection{Business Process Management (BPM)}

O Business Process Management (BPM) como campo de pesquisa tem se desenvolvido continuamente desde que surgiu, como fruto de experiências práticas de profissionais de ciências da computação e administrativas. Como conceito, sua compreensão, tanto no campo da pesquisa científica quanto na prática administrativa, varia daquele puramente orientado pela Tecnologia da Informação (TI) a uma compreensão holística dos processos de negócio (BROCKE; SCHMIEDEL, 2011; RECKER; MENDLING, 2016). De técnica, o BPM tem sido promovido a cultura de gestão voltada a permitir às organizações aumentarem a produtividade, alcançarem excelência operacional e reduzirem custos, gerando valor para o cliente tanto em empresas privadas como em organizações públicas (RECKER; MENDLING, 2016). Consigo, o BPM trouxe a disseminação de modelos, métodos e ferramentas que dão suporte às práticas de mapeamento, análise, implantação e revisão dos processos de negócios.

Vale notar que as abordagens holísticas do BPM consideram, de fato, múltiplos aspectos organizacionais, percebendo processos como o núcleo central a partir do qual os negócios são conduzidos, com o efetivo envolvimento de gestores e demais atores envolvidos. Assim, a cultura organizacional é reconhecida como elemento essencial, que influencia e é influenciada pelo BPM; de fato, a cultura é reiteradamente referida ora como obstáculo, ora como fator de sucesso em diferentes iniciativas de BPM (BROCKE; SCHMIEDEL, 2011; SCHMIEDEL; BROCKE; RECKER, 2015).

Dentre os estudos teóricos, Schmiedel, Brocke e Recker (2015) se destacam na proposição de três conceitos fundamentais: (I) Cultura BPM: refere-se a uma cultura que apoia a consecução de objetivos de BPM, ou seja, a busca por processos de negócios eficientes e eficazes; (II) Contexto Cultural: refere-se ao ambiente que uma iniciativa de implantação da estratégia de negócio BPM encontra, na prática. Ele seria composto, na verdade, por vários culturais, incluindo valores regionais/nacionais, práticas e vivências organizacionais ou mesmo de linguagens de setores específicos; (III) Adaptação Cultural: refere-se à congruência básica entre a cultura BPM e o contexto cultural, representando, assim, pré-requisito para uma abordagem de BPM bem-sucedida nas organizações.

Já em relação às evidências empíricas, Jurisch et al. (2013) realizaram levantamento de 128 estudos de caso, envolvendo projetos de reengenharia de processos em organizações públicas e privadas; observou-se que os projetos foram considerados exitosos em $60 \%$ das entidades públicas e em $70 \%$ das privadas; além, disso, em um maior número de instituições públicas os projetos ficaram incompletos (23\%), na comparação com as demais (14\%). Allen e Fifield (1999), por sua vez, investigaram estudos de casos sobre o redesenho de processos em instituições de ensino superior no Reino Unido, concluindo que a cultura - reiteradamente ela - e a estrutura 
Maia Filho, L. F. A.; Pinho, M. A. B.

Revista Gestão.Org, v. 16, Edição Especial, 2018. p. 293-306

ISSN 1679-1827

http://www.revista.ufpe.br/gestaoorg

organizacionais das universidades limitavam o grau de mudança alcançável.

O prefácio de Brocke e Rosemann (2014), sobre uma seção do influente Handbook of Business Process Management, não inovava ao chamar atenção para o "pouco reconhecido - embora vital - campo de pessoas e culturas organizacionais" na literatura especializada. Mas, na referida seção, Harrison-Broninski (2014) salientam a necessidade de distinção entre os processos centrados nas pessoas (como o processamento de pedidos comerciais, a aprovação de empréstimos ou o atendimento ao cliente, em que indivíduos interagem com políticas organizacionais protocolos, banco de dados e, apenas de forma limitada, com outras pessoas) e os chamados Human-Driven Processes (HDP's) em que a busca por colaboração, adaptação e inovação tornam indispensáveis certas habilidades humanas dialógicas e de liderança.

Não é difícil perceber que algumas das principais etapas do mapeamento de processos constituem, elas mesmas, HDP's - particularmente, a realização de entrevistas com gestores e atores em organizações complexas como universidades, departamentos de pesquisa, ou agências proponentes/executoras de políticas públicas; são ambientes em que, não raras vezes, atividades específicas são executadas por profissionais com elevado grau de especialização, a partir de conhecimentos, habilidades e mesmo de modelos mentais pouco compartilhados por outras pessoas envolvidas na execução do mesmo processo (GUISE et al., 2017).

Nesse sentido, o presente estudo pode ser interpretado como um passo na direção reconhecida por Eikebrokk et al. (2011); combinando ampla revisão da literatura e entrevistas com 34 gestores, com a aplicação de sondagem a uma amostra de 74 empresas, identificou-se uma gama de fatores, de posturas pessoais a contextos organizacionais, associados à aceitação e ao uso da modelagem de processos nas organizações. É natural, portanto, supor que as iniciativas de mapeamento de HDP's tenham ganhos ao incorporar, desde seu planejamento, elementos táticos de natureza econômico-comportamental e, de forma transparente e ética, favoreçam o engajamento e a plena cooperação das equipes no diagnóstico organizacional.

\subsection{A entrevista na descoberta de processos}

O chamado ciclo BPM é composto, conforme amplo conhecimento, pelas etapas de identificação, descoberta, análise, redesenho, implementação, execução, monitoramento e adaptação dos processos organizacionais (DUMAS et al., 2013). Entretanto, Hunt (1996) salienta que o impulso à transformação organizacional na gestão de processos advém de um perceptível contraste entre o estado original das práticas e rotinas organizacionais (modelo $A S I S$, ou "como é") e um estado futuro desejável (modelo TO BE, ou "como deve ser"); nesse sentido, parece oportuno considerar muito detidamente as atividades cuja execução, a princípio, poderiam ampliar as chances de se ter uma honesta e completa avaliação dos membros da organização sobre as eventuais limitações de suas práticas; em outras palavras, negligenciar, na fase crítica de descoberta do processo, a existência de complexas dinâmicas humanas, muitas de natureza interativa, pode tornar infrutíferos todos os esforços subsequentes, levando à proposição de mudanças inoportunas - se não ineficazes, ou até contraproducentes.

Dentre as possíveis fontes primárias para se levantar informações sobre atores, parâmetros e circunstâncias relativas à execução dos processos organizacionais, destacam-se a entrevista, a observação direta e a aplicação de questionários (OLIVEIRA, 2011; BALLESTERO-ALVAREZ, 2011). Em particular, a entrevista constitui técnica de coleta de dados especialmente adequada para mapear práticas, crenças, valores e ambientes sociais específicos, como os de diferentes setores das organizações entre os quais as possibilidades de conflitos e contradições não tenham sido - até então - claramente explicitados (De SORDI, 2014).

A entrevista se configura como uma conversação bidirecional iniciada por um entrevistador para obter informações de um respondente (COOPER; SCHINDLER, 2003). Como em outras técnicas de levantamento de dados, existem vantagens reais e limitações na entrevista pessoal. Seu principal valor está na profundidade das informações e nos detalhes que ela pode alcançar. Sobretudo, os entrevistadores são capazes de "observar" os diferentes contextos organizacionais e avaliar se a qualidade e a quantidade de informações são, de alguma forma, prejudicadas pela capacidade ou pela disposição em cooperar dos respondentes.

Apesar de as entrevistas poderem criar um senso de participação corresponsabilidade no processo de modelagem e documentação de processos de negócios, agendar e realizar entrevistas pode levar mais tempo do que outros métodos. Por exemplo, essa abordagem requer uma interrupção de tempo e obrigações normais dos participantes, o que pode trazer problemas à aceitação do método - já que outras tarefas e compromissos acabam tendo que ser reagendados. Também pode ser difícil construir um fluxo de processo coerente e coeso, na eventual condução de múltiplas entrevistas separadas, que tendem a registrar diferentes pontos de vista, sem uma visão integrada. Assim, a entrevista em grupo, conduzida por um facilitador, pode se mostrar mais efetiva para gerar discussões e obter um 
preciso levantamento das informações-chave (ABMP BRASIL, 2013).

Por outro lado, não se pode negar que há muitas razões para uma cooperação parcial e insuficiente por parte do(s) entrevistado(s), como, por exemplo, quando ele mesmo não vê valor na sua participação; quando ele teme a experiência da entrevista por alguma razão pessoal; ou mesmo quando supõem que o assunto abordado na entrevista seja muito delicado, tornando a entrevista embaraçosa ou até constrangedora (COOPER; SCHINDLER, 2003).

Ainda que não se pretenda desenhar uma estratégia BPM perfeita, composta de táticas dialógicas ideais às mais diferentes circunstâncias encontradas no mapeamento de processos, parece razoável supor que a cuidadosa comunicação no momento do primeiro contato com os entrevistados é fundamental para a obtenção de bons resultados. É nesse momento que o pesquisador deve deixar claro ao entrevistado não apenas o compromisso da alta administração, mas também sua atitude profissional, sua postura ética e uma visão global dos procedimentos que pretende adotar para a pesquisa - no caso específico, no levantamento de informações sobre determinado(s) processo(s). Não por acaso, a confecção e a leitura acompanhada de fluxogramas são as práticas mais inequivocamente associadas ao BPM. Ao focar objetivos de negócio e fazê-lo de forma transparente, as equipes responsáveis pelo BPM podem, de fato, criar um ambiente saudável para que o levantamento de informações e a consequente intervenção no processo prospere (ABMP BRASIL, 2013).

\subsection{A Economia Comportamental e o arcabouço MINDSPACE}

A Economia Comportamental é uma área de pesquisa de acelerado crescimento que propõe modificar as teorias econômicas convencionais e considerar a natureza psicológica das preferências e do juízo que, em última instância, impactam o (suposto) cálculo racional, a força-de-vontade e mesmo a ganância dos indivíduos (CAMERER; MALMENDIER, 2012).

Samson (2015) esclarece que, segundo a Economia Comportamental, as pessoas nem sempre são indivíduos egoístas e calculistas, com preferências estáveis e bem-definidas, de modo que muitas de nossas escolhas não são o resultado de deliberação cuidadosa. Em vez disso, nosso pensamento tende a sofrer com conhecimento e cognição insuficientes, além de ser impactado de modo significativo pelo contexto das decisões. Nós somos inconscientemente influenciados pela informação imediatamente disponível na memória, por sentimentos gerados automaticamente e por informações mais evidentes ao nosso redor, e nós ainda vivemos no momento, no sentido de que resistimos a mudanças, somos pouco capazes de prever preferências futuras, somos suscetíveis a memórias distorcidas e somos afetados por estados psicológicos e emocionais. Ainda segundo Samson (2015), a Economia Comportamental reconhece que somos animais sociais, com preferências sociais, como as expressas na forma de confiança, altruísmo, reciprocidade e senso de justiça; por fim, temos um desejo por coerência pessoal e, em geral, um certo apreço por normas sociais.

Nas últimas duas décadas, a Economia Comportamental floresceu e se expandiu como campo de pesquisa, com suas implicações tendo influenciado instituições e políticas públicas em todo o mundo (WORLD BANK, 2015). Naturalmente, a modelagem diagnóstica e o redesenho de HDP's para consideração formal de aspectos favoráveis/desfavoráveis à colaboração têm muito a ganhar com os achados de investigações recentes das ciências comportamentais. Afinal, nos mais diferentes contextos, de campanhas publicitárias ao redesenho de políticas públicas, um conjunto expressivo de regularidades comportamentais têm se mostrado mais influente e relevante do que indicaria o senso comum (DOLAN et al., 2012).

Para Dolan et al. (2012) em termos gerais, existem duas maneiras de pensar sobre o comportamento individual e, consequentemente, sobre como seria possível influenciá-lo. O primeiro modelo, chamado cognitivo, é baseado em influenciar o que as pessoas pensam, julgam ou avaliam conscientemente. Parte-se do pressuposto de que é possível influenciar o comportamento através de uma "mudança de mentes", ou seja, através de uma reflexão consciente sobre o ambiente circundante. Em contraste, há o modelo que foca nos processos mais automáticos de julgamento e influência: a maneira como as pessoas respondem ao ambiente. Isso direciona o foco da atenção menos para os fatos e informações, e mais para o contexto em que as pessoas agem. Esse modelo de comportamento é chamado de contextual.

Décadas de pesquisas mostram que gestores estão sujeitos a vieses sistemáticos, como qualquer pessoa, que podem levar a erros dispendiosos para suas organizações (LIU et al., 2017). Abordagens convencionais para eliminar esses vieses focavam em levantar estratégias para modificar a mente do tomador de decisão. Assim, se as pessoas pudessem reconhecer as habilidades cognitivas que utilizam em seus processos de tomada de decisão - atuando de uma forma mais lógica e cuidadosa, mais semelhante ao lendário tomador de decisão racional - melhores 
Maia Filho, L. F. A.; Pinho, M. A. B.

Revista Gestão.Org, v. 16, Edição Especial, 2018. p. 293-306

ISSN 1679-1827

http://www.revista.ufpe.br/gestaoorg

resultados poderiam ser atingidos. Em suma, os gerentes precisariam deixar de lado esses vieses, através de educação e treinamento (LIU et al., 2017).

Pesquisas recentes sugerem, porém, que uma tentativa de "desenviesar" o pensamento dos gestores é um processo insuficiente porque ele lida apenas com os pensamentos lentos, deliberados e conscientes (KAHNEMAN, 2011). No entanto, nosso sistema de tomada de decisão inconsciente, rápido e automático, é muitas vezes crucial. Os processos rápidos de raciocínio e decisão fornecem, muitas vezes, a lente através da qual entendemos um problema estratégico (por exemplo, a atratividade de um comportamento cooperativo, ou a reação diante de aparentes ameaças de um inimigo potencial); nesse caso concentraríamos nossa atenção em aspectos específicos, tomando decisões mais intuitivas - que descartam alternativas envolvendo cálculos complexos, e elevam outras ao topo da fila (KAHNEMAN, 2011).

Executivos e pesquisadores vêm dedicando atenção crescente a fenômenos como os efeitos apresentação e enquadramento (SKARLICKI; RUPP, 2010); os papéis da credibilidade e da reputação (FERRIS et al., 2003); o exaurimento de força-de-vontade e a procrastinação (FROMEL et al. 2014); a pressão dos pares (peer pressure), o viés de miopia ou a aversão à perda (loss aversion) - entre tantos outros (GALAVAN et al., 2017). Ao invés de serem relegados genericamente a aspectos indesejáveis ou inoportunos de uma "cultura organizacional", ou considerados posturas pessoais/profissionais inadequadas, esses aspectos previsíveis do comportamento humano e seus impactos podem e devem ser previamente considerados no planejamento de ações estratégicas (LIU et al., 2017), como na modelagem de HDP's.

A estratégia acima introduzida está também na base do que se convencionou chamar arcabouço MINDSPACE, que visa repensar o desenvolvimento de políticas públicas com foco sobre o estímulo a novos comportamentos (DOLAN et al., 2012). O termo, em tradução livre, faz referência à mentalidade dos indivíduos direta ou indiretamente envolvidos no sucesso de uma ação coletiva, de interesse público; mais precisamente, trata-se de um acrônimo desenvolvido pelo Behavioral Insight Team, órgão de assessoria e inteligência do Governo Britânico, para as seguintes expressões (em língua inglesa): mensageiro ("Messenger"); incentivos ("Incentives"); normas sociais ("Norms"); critério-padrão de tratamento ("Default"); destaque ("Salience"); efeito-apresentação ("Priming"); afeto (“Affect"); compromisso ("Commitment"); e auto-imagem ("Ego").

Cada um dos nove aspectos MINDSPACE tem sido considerado possível vetor tático no redesenho de ações específicas de interesse coletivo; busca-se estimular mudanças voluntárias de comportamentos, diante de objetivos transparentes e relativamente consensuais.

Desde a inversão dos critérios legais para que um determinado cidadão seja considerado doador de órgãos - um novo padrão (Default) de tratamento, em que todos são doadores até que se manifestem em contrário - até a submissão de dados anônimos na conta de luz, pelos quais uma pessoa pode comparar seu consumo de energia com os dos vizinhos - promovendo destaque e favorecendo uma autoimagem positiva -, abordagens econômicocomportamentais como a do MINDSPACE têm se mostrado eficazes e muito bem recebidas em diferentes contextos, há algum tempo (SCHAAP et al., 2008). Considerar tais aspectos em etapa crucial do mapeamento de processos organizacionais, é, portanto, caminho promissor para o aprimoramento de instituições públicas, no sentido de lhes oferecer reais oportunidades de aprendizagem e melhoramento organizacionais.

\section{Procedimentos Metodológicos}

Como descrito anteriormente, projetos de mudança organizacional que envolvem amplos esforços de mapeamento/revisão de processos de negócios tendem a encontrar significativa resistência "cultural" em certos ambiente, sobretudo no setor público; é oportuno, portanto, que sejam cuidadosamente planejadas e executadas certas atividades críticas capazes de convidar, justificar e valorizar o engajamento plenamente colaborativo das equipes com quem ocorrerão as interações. Em outras palavras, trata-se de modelar formalmente o processo da entrevista, levando em conta a previsível existência de fatores psicossociais com potencial de favorecer ou comprometer a qualidade e a profundidade do diálogo.

O contexto em que o presente estudo se desenvolveu teve grande impacto na sua natureza de pesquisa-ação política (TRIP, 2005), e permite uma melhor compreensão dos métodos a serem detalhados, logo em seguida. Em 2016, o Fórum de Pró-Reitores de Planejamento e Administração das universidades federais brasileiras (FORPLAD) criou um Grupo de Trabalho para estudar, consolidar e promover as melhores práticas associadas à gestão de processos naquelas entidades - um dos autores do presente artigo coordenou o referido Grupo de Trabalho por cerca de 2 
http://www.revista.ufpe.br/gestaoorg

anos. Dentre outras necessidades, associadas inclusive à realização de ciclos coordenados para revisão simultânea de processos específicos em múltiplas organizações, destacava-se a de reunir manuais, guias e roteiros que, editados e/ou combinados, pudessem constituir um arcabouço referencial comum - evitando retrabalhos e, possivelmente, custos. No entanto, já com a análise dos primeiros materiais utilizados pelas universidades pioneiras na gestão de processos, tornou-se evidente a escassez de considerações sobre os aspectos relativos ao planejamento prévio e meticuloso das interações inerentes ao próprio mapeamento de processos.

Além disso, as vivências dos autores do presente estudo na execução de um projeto de extensão de finalidade convergente - que acabou adquirindo função de projeto-piloto para a acima referida articulação nacional do FORPLAD - confirmavam a necessidade do que Tripp (2005) definiu como pesquisa-ação política: aquela que se dedica a considerar aspectos da cultura organizacional envolvidos e/ou limitadores da mudança, perpassando a necessidade de se trabalhar com ou contra outros para exercícios de poder.

Diante do contexto acima descrito e tendo em vista os objetivos do presente estudo, a metodologia empregada se dividiu em 4 etapas:

I. Levantamento e a análise crítica de roteiros, recomendações e white papers referentes à etapa de descoberta de processos nas organizações, buscando identificar - sempre que possível - o grau de importância atribuído a fatores comportamentais; especial atenção foi dedicada, por um lado, aos materiais editados (e disponibilizados em sítios eletrônicos institucionais) pelos Escritórios de Processos da universidades federais brasileiras em operação no ano de 2018; e, por outro lado, ao influente trabalho de compilação e análise diagnóstica de casos realizado por Verner (2004).

II. A elaboração e a realização de sucessivas edições de um fluxograma relativo ao processo de entrevista com gestores/atores participantes em um projeto de extensão voltado para mapeamento de processos na gestão do ensino; participaram de três reuniões e contribuíram para a validação do modelo um total de 5 professores doutores das áreas de economia e administração, 3 servidores técnico-administrativos, 3 discentes de programas de pós-graduação e 5 discentes de graduação - todos vinculados à UFRPE.

III. Revisita aos arquivos de áudios gravados durante as entrevistas de mapeamento de processos, realizadas no referido projeto de extensão; o procedimento visou reconhecer, na cuidadosa análise das falas de todos os participantes, riscos e oportunidades associadas ao grau de engajamento e disposição à cooperação por parte dos entrevistados;

IV. A revisão final do fluxograma relativo ao processo de entrevista e descoberta, incluindo (e dando prioridade) a novas atividades voltadas à mitigação de riscos e ao aproveitamento de oportunidades para mais efetiva colaboração - em linha com o arcabouço MINDSPACE.

Os resultados alcançados com a execução criteriosa dessas etapas são discutidos, a seguir.

\section{Resultados}

\subsection{Análise de documentos orientadores à condução de entrevistas para descoberta de processos}

Foram inicialmente analisados os documentos metodológicos, materiais de apoio, guias e roteiros editados (e disponibilizados publicamente em meio eletrônico) por Escritórios de Processos de 7 universidades federais brasileiras, a saber: UFPEL, UFPE, UFMT, UFJF, UNIPAMPA, UFSM e UFRGS.

A informações contidas no Quadro 1 (abaixo) não deixam margem a dúvida: a maioria dos materiais utilizados por aquelas IFES traz mínimas recomendações em relação aos aspectos de natureza comportamental que podem favorecer ou prejudicar a quantidade e a qualidade das informações coletadas via entrevistas. Como exceção, o documento editado pela equipe da Universidade Federal de Pelotas (UFPEL) revela ciência e atenção à natureza sensível dos aspectos comportamentais, em dois pontos: ao considerar - e definir atividades específicas - a formação de expectativa por parte dos gestores envolvidos e ao descartar sumária e antecipadamente o uso de gravadores (de áudio) no decorrer da entrevista, provavelmente por antever e para evitar possível inibição na participação dos entrevistados.

Merece menção, ainda, a referência ao conceito Engajamento Sustentável pelo documento da Universidade Federal de Santa Maria (UFSM), considerando como valor organizacional o "bem-estar físico, interpessoal e emocional no trabalho". Pressupõe-se que tal valor oriente o diálogo para diagnóstico organizacional, embora não se considere de forma explícita a influência de relutâncias e indisposições à cooperação no decorrer de entrevistas. 
Maia Filho, L. F. A.; Pinho, M. A. B.

Revista Gestão.Org, v. 16, Edição Especial, 2018. p. 293-306

ISSN 1679-1827

http://www.revista.ufpe.br/gestaoorg

\begin{tabular}{|c|c|c|}
\hline Instituição & Descrição do Material & Destaques relativos à condução de entrevistas \\
\hline UFPEL & $\begin{array}{l}\text { Apresentação-Tutorial de } \\
\text { Mapeamento }\end{array}$ & $\begin{array}{ll}\text { - } & \text { Reunião prévia com gestor máximo, para } \\
\text { apresentação da metodologia } \\
\text { - } & \text { Adotar estruturação mínima para a entrevista } \\
\text { - } & \text { Registrar a expectativa do(s) gestor(es) } \\
\text { - } & \text { Não utilizar gravador }\end{array}$ \\
\hline UFPE & $\begin{array}{l}\text { Metodologia de Gestão de } \\
\text { Processos }\end{array}$ & $\begin{array}{l}\text { - Condução de "Reunião de Entendimento da } \\
\text { Situação", amplo escopo, com todos os envolvidos } \\
\text { - Reunião de validação das informações (fluxograma) } \\
\text { e coleta de dados quantitativos sobre os processos }\end{array}$ \\
\hline UFMT & $\begin{array}{l}\text { Manual de Gestão de } \\
\text { Processos }\end{array}$ & $\begin{array}{l}\text { - Coleta de informações envolve "Brainstorming, } \\
\text { grupo de trabalho com foco no processo, entrevista, } \\
\text { cenário, questionário e 5W2H." } \\
\text { - Princípios (BPM CBOK) incluem "Envolva o maior } \\
\text { número de pessoas e trabalhe em paralelo" }\end{array}$ \\
\hline UFJF & $\begin{array}{l}\text { Modelo de Governança de } \\
\text { Processos }\end{array}$ & $\begin{array}{l}\text { Etapa Mapeamento e Diagramação do processo atual } \\
\text { (as is) envolveria: entrevistas com os executores do } \\
\text { processo; entrevistas com os gestores funcionais; } \\
\text { observação da execução das atividades; reuniões de } \\
\text { grupos focais (executores e gestores do processo) }\end{array}$ \\
\hline UNIPAMPA & $\begin{array}{l}\text { Manual de Transformação de } \\
\text { Processos de Negócios }\end{array}$ & $\begin{array}{l}\text { - Definição objetiva dos papéis de "Facilitador", que } \\
\text { auxilia a interação entre as diversas áreas, e de } \\
\text { "Modelador", que constrói o modelo do processo } \\
\text { - O levantamento de info ocorre via entrevistas com } \\
\text { os envolvidos no processo, observação do processo } \\
\text { sendo executado, leitura de padrões e normas }\end{array}$ \\
\hline UFSM & $\begin{array}{c}\text { Guia de Mapeamento de } \\
\text { Processos }\end{array}$ & $\begin{array}{ll}\text { - } & \text { Aplicação prévia de formulários 5W2H e MASP } \\
\text { (Método de Análise e Solução de Problemas) } \\
\text { - } & \text { Entrevista dirigida, orientada por formulário próprio } \\
\text { - } & \text { Referência a Engajamento Sustentável (conceito que } \\
\text { envolve o "bem-estar físico, interpessoal e } \\
\text { emocional no trabalho") }\end{array}$ \\
\hline UFRGS & Apresentações Diversas & $\begin{array}{l}\text { - Diagramação de processos não críticos conduzida } \\
\text { pelos próprios atores, que dispõem de Curso EAD } \\
\text { - Processo de análise e validação dos processos } \\
\text { mapeados a partir de entrevistas estruturadas, } \\
\text { conforme formulários padronizados }\end{array}$ \\
\hline
\end{tabular}

Quadro 1 - Orientações relativas à condução de entrevistas em IFES.

Fonte: Elaboração própria.

Quanto ao influente artigo técnico de Verner (2004), fatores e aspectos comportamentais são, ali, claramente associados a ocasionais fracassos na realização de oficinas (workshops) para a descoberta e análise diagnóstica de processos. Listadas entre as frequentes razões, estão a descrença dos próprios gerentes na descoberta eficiente e efetiva dos processos em tais reuniões, além da dificuldade muito comum para se reunir as pessoas-chave, 
http://www.revista.ufpe.br/gestaoorg

disputando seu tempo e atenção com uma ampla gama de atividades prioritárias. Tais considerações subsidiam a recomendação de que seja assegurado, pelas lideranças na organização, um grau muito elevado de priorização e patrocínio (sponsorship) das iniciativas para mapeamento de processos, sem as quais atitudes verdadeiramente colaborativas não ocorreriam. Verner (2004) ainda reconhece que alguns participantes tendem a registrar relutância em expor fragilidades dos processos atuais, temendo que suas reputações sejam comprometidas, ou que possam até mesmo sofrer represálias "políticas" em seus setores/departamentos. No entanto, as recomendações para esses casos não vão além das que envolvem comunicação cuidadosa com todas as partes interessadas (stakeholder engagement).

\subsection{Modelo comportamental para condução de entrevistas diagnósticas de processos}

O fluxograma completo, que sintetiza um modelo de processo de entrevista inspirado pelo arcabouço MINDSPACE, encontra-se ao final desta subseção. Por se tratar de um diagrama grande e relativamente rico em detalhes, recortes ilustrativos do fluxograma permitem a consideração de elementos específicos, conforme detalhadamente discutidos em Dolan et al. (2012), dentre os quais merecem ênfase:

a) O DESTAQUE ("Salience"), no arcabouço MINDSPACE, busca direcionar a atenção de um determinado público a aspectos novos, particularmente relevantes e de fácil acesso; se reconhece que nossas mentes recebem e precisam filtrar continuamente uma grande quantidade de informações e estímulos; a natureza necessariamente colaborativa das atividades para análise diagnóstica de processos está presente em quase todas as etapas, a começar pela definição de que cabe ao gestor da área/setor - desde os primeiros momentos - reconhecer (valorizar), na sua equipe, os executores de atividades com maiores capacidades de contribuir. No entanto, é na primeira reunião com múltiplos membros da equipe de execução que a ênfase à centralidade da atitude colaborativa é mais evidente, conforme a Figura 1.

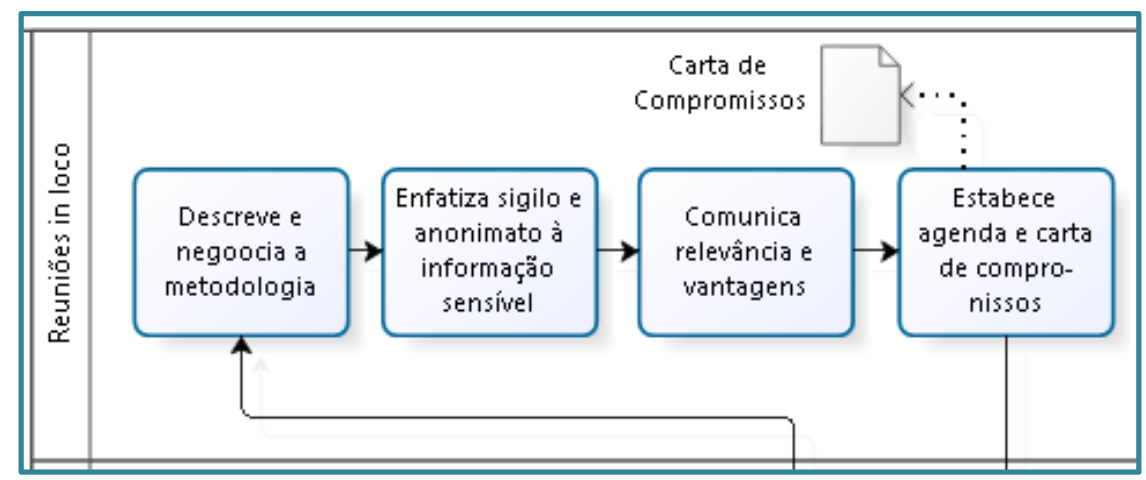

Figura 1 - Ênfases para valorização e favorecimento à colaboração.

Fonte: Elaboração própria.

Entende-se que a metodologia deve ser não apenas apresentada, mas literalmente negociada com os participantes na $1^{\mathrm{a}}$ reunião; o destaque a essa atitude traz um primeiro sinal claro de que o diálogo não será restrito ou direcionado de forma impositiva, ao longo do projeto.

b) A necessidade de COMPROMISSOS (“Commitment") decorre da procrastinação, uma tendência humana amplamente documentada e facilmente reconhecida em nossas vivências cotidianas; acordos estabelecidos por escrito entre a equipe de mapeamento e os demais envolvidos no processo pretendem assegurar mútua prioridade e recíproca tempestividade na consecução das diferentes etapas. A partir de tal "Carta de Compromissos" (Figura 1), as expectativas e as responsabilidade dos diferentes participantes tornam-se públicas e, presumivelmente, de amplos conhecimento e concordância;

c) Ocorrem de modo a INCENTIVAR ("Incentives") níveis elevados de engajamento e cooperação, entre outras iniciativas: uma equilibrada descrição dos ganhos a serem proporcionados (Figura 1); a inserção de circunstâncias e trâmites formais para tratamento sigiloso e anônimo de informações sensíveis (Figura 2), eliminando temores de retaliações por comentários e análise mais críticas; o reconhecimento pessoal e imediato, de forma proporcional à qualidade da participação (Figura 4). Note-se que ao prever e apresentar canais especiais para a submissão de informações sensíveis, com potencial de expor 
Maia Filho, L. F. A.; Pinho, M. A. B.

Revista Gestão.Org, v. 16, Edição Especial, 2018. p. 293-306

ISSN 1679-1827

http://www.revista.ufpe.br/gestaoorg

fragilidades da organização ou da própria equipe, confere-se destaque também a disposição em refletir profunda e honestamente sobre os desafios da organização - em linha com que porpõem Near e Miceli (1995).

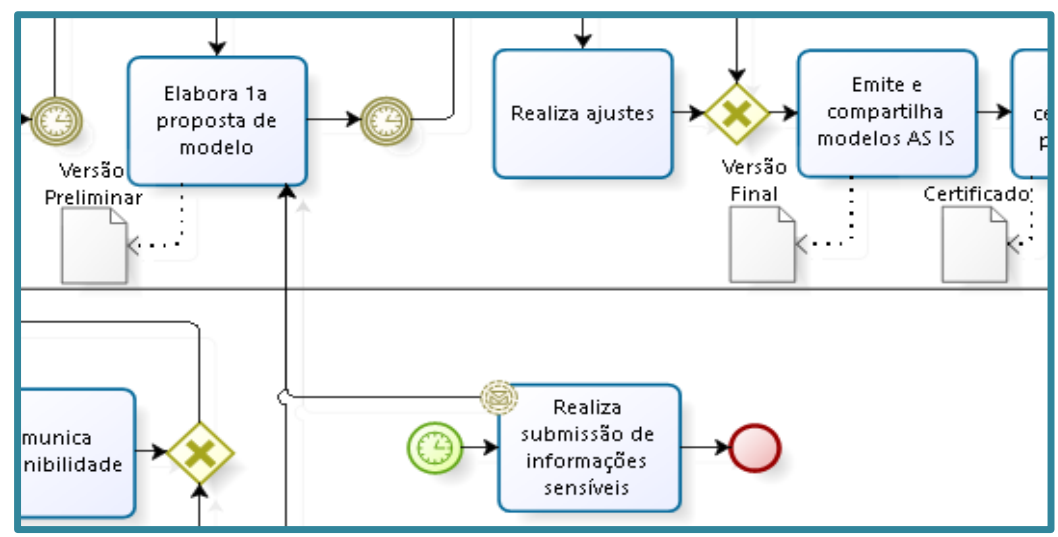

Figura 2 - Previsão de canais anônimos para informações sensíveis

Fonte: Elaboração própria.

d) A prerrogativa de validação final do modelo AS IS pelos gestores e atores responsáveis participante da(s) entrevista(s) (Figura 3), valoriza e confere motivos de ORGULHO e SATISFAÇÃO ("Ego"), por parte dos que colaboram efetivamente com a transformação organizacional; a própria existência dos certificados de participação, anunciada e incluída na Carta de Compromissos, funciona como elemento adicional de incentivo à colaboração.

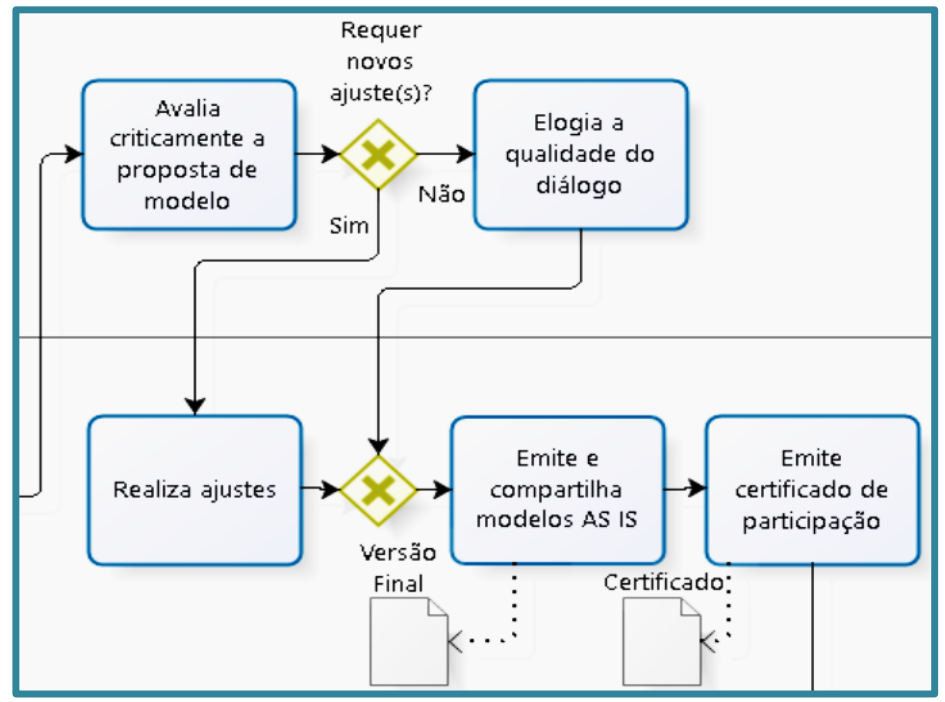

Figura 3 - Validação do modelo AS IS por toda equipe envolvida.

Fonte: Elaboração própria.

e) O registro atencioso de APREÇO e GRATIDÃO (“Affect") pelos esforços de reflexão e detalhamento que claramente se destinarem a subsidiar significativas proposições de aprimoramento do processo sob investigação (Figura 4).

Por fim, vale ressaltar que, conjuntamente, os elementos de favorecimento à colaboração inspirados no arcabouço 
MINDSPACE tornam o modelo completo abaixo (Figura 5) uma proposta claramente inovadora, inclusive pelo seu foco no reconhecimento de características muito específicas do comportamento humano.

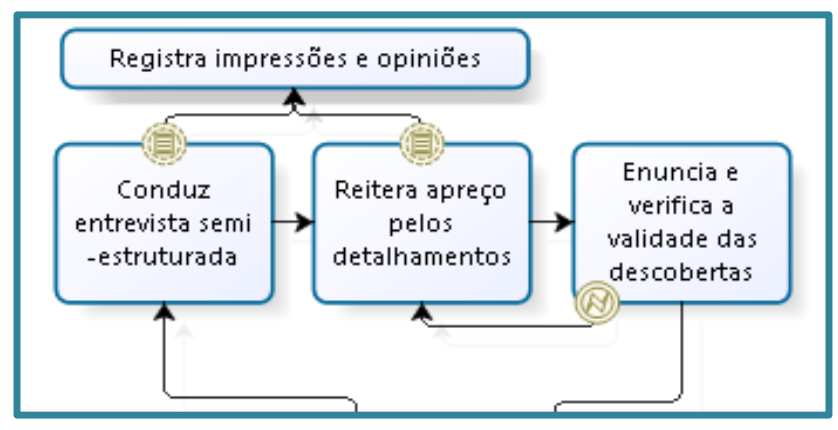

Figura 4 - Valorização e registro de apreço pela precisão.

Fonte: Elaboração própria.

Contudo, ainda que já reúna elementos suficientes para ser considerada tática promissora pelos gestores de uma determinada organização, a abordagem tem muito a ganhar ao seguir os demais passos das intervenções MINDSPACE em políticas públicas: o estabelecimento de projetos-piloto, a flexibilidade no planejamento e na execução das ações e a cuidadosa avaliação dos resultados - subsidiando o contínuo aprimoramento da estratégia (DOLAN, 2010). Embora fuja ao escopo do presente trabalho, aquelas serão suas extensões indispensáveis pesquisas em andamento. 
Maia Filho, L. F. A.; Pinho, M. A. B.

Revista Gestão.Org, v. 16, Edição Especial, 2018. p. 293-306

ISSN 1679-1827

http://www.revista.ufpe.br/gestaoorg

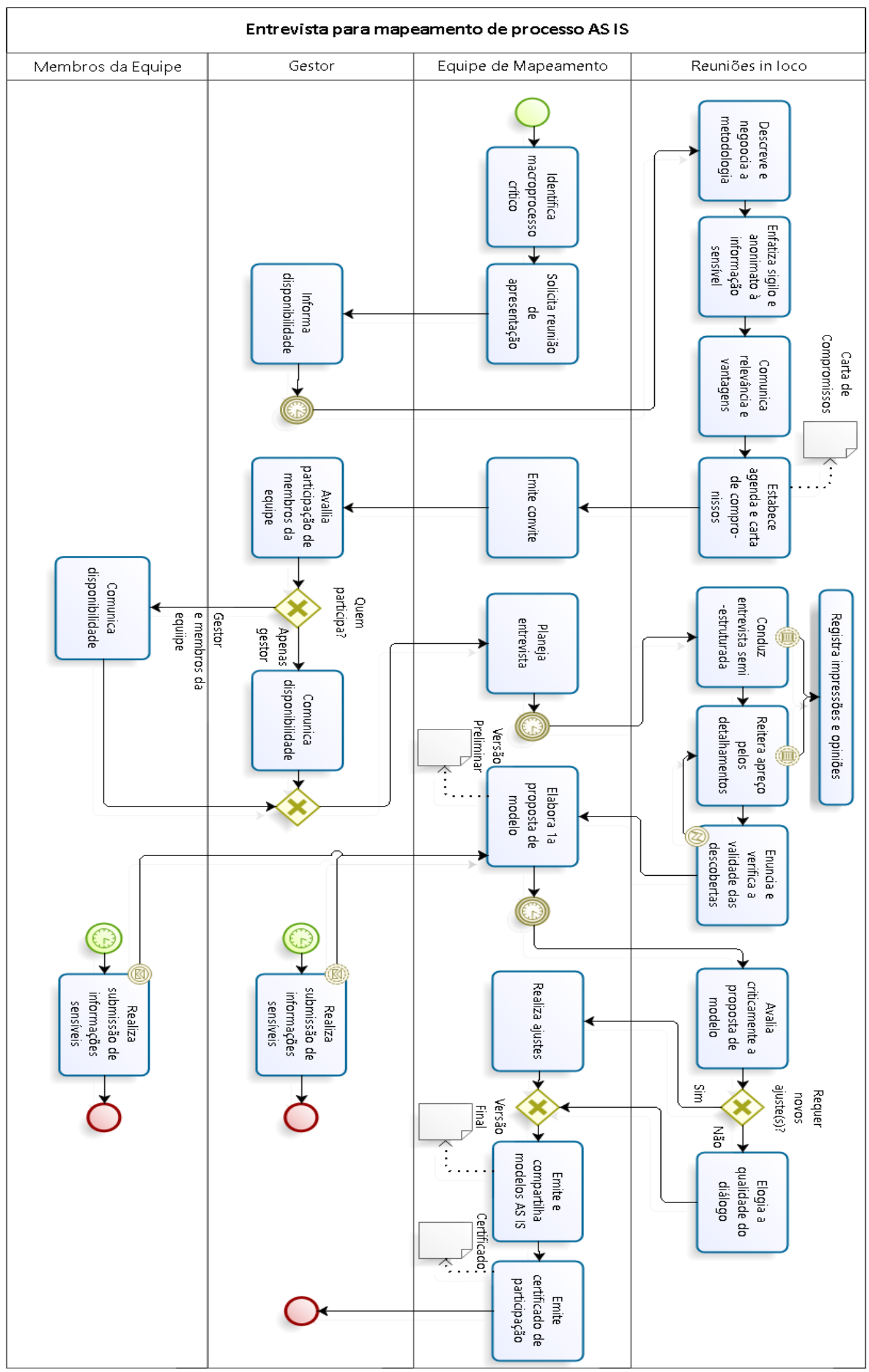

Figura 5 - Fluxograma completo de entrevista inspirada no arcabouço MINDSPACE.

Fonte: Elaboração própria. 


\section{Conclusões}

Dentre os dez princípios essenciais à gestão de processos destacados por Brocke et al. (2014), ao menos três deles lidam diretamente com possíveis obstáculos ao engajamento dos atores: a consciência do contexto; a qualidade do diálogo e da interação entre os executores; e o entendimento comum dos processos. O arcabouço MINDSPACE, que tem se revelado significativa inovação no desenho de políticas públicas, reúne condições claramente favoráveis de assegurar tratamento apropriado a tais princípios e, assim, se tornar fator diferencial em projetos de transformação nas organizações de relativa complexidade, como as IFES. O presente artigo revelou precisamente como adaptá-lo, incorporando arranjos complementares e com fundamentação conceitual às entrevistas de descobertas de processos; consolidam-se, de modo formal, as boas práticas apenas parcialmente reconhecidas até aqui - nos relatos de vivências em torno do mapeamento de processos.

Em vez de serem relegados à uma genérica "cultura organizacional", ou atribuídos a posturas pessoais e profissionais (in)adequadas de indivíduos, os fatores comportamentais envolvidos na execução de processos organizacionais críticos - bem como seus impactos - devem ser investigados como aspecto passíveis de planejamentos e gestão. Quando expressos formalmente na linguagem BPM, eles tendem a contribuir com uma interpretação muito mais precisa e profunda da real distribuição de responsabilidades nas tarefas colaborativas; em última instância, diagnósticos assim construídos poderão melhor orientar a escolha entre caminhos alternativas de mudança organizacional e, consequentemente, promover não apenas a eficiência, mas principalmente a efetividade.

\section{Referências}

ALLEN, D. K.; FIFIELD, N. (1999) Re-engineering change in higher education. Information Research, 4(3). http://informationr.net/ir/4-3/paper56.html

ABMP BRASIL (2013). BPM CBOK: Gerenciamento de processos de negócio, corpo comum de conhecimento $A B P M P B P M C B O K$ v. 3. São Paulo: ABMP Brasil.

BALlESTERO-ALVAREZ, M. E. (2011) Manual de organização, sistemas e métodos: abordagem teórica e prática da engenharia da informação. 5. Ed. São Paulo: Atlas.

BANDURA, A. (1992) Social cognitive theory of moral thought and action. In: Handbook of moral behavior and development (1), pp. 45-103.

BREHM, J.; GATES, S. (1999) Working, shirking, and sabotage: Bureaucratic response to a democratic public. University of Michigan Press.

BROCKE J. V.; ROSEMANN, M. (eds) (2014) Handbook on business process management (2). Heidelberg: Springer.

BROCKE, J. V.; SINNL, T. (2011). Culture in business process management: a literature review. Business Process Management Journal, 17(2), 357-378. https://doi.org/10.1108/14637151111122383.

BROCKE, J. V.; SCHMIEDEL, T.; RECKER, J.; TRKMAN, P.; MERTENS, W.; VIAENE, S. (2014). Ten principles of good business process management. Business process management journal, 20(4), 530-548. https://doi.org/10.1108/BPMJ-06-2013-0074

CAMERER, C.; MALMENDIER, U. (2012) Behavioral Economics of Organizations. In: P. Diamond and H. Vartiainen (eds.), Behavioral Economics and Its Applications. New Jersey: Princeton University Press.

COOPER, D. R.; SCHINDLER, P. S. (2003) Métodos de pesquisa em administração. 7. ed. Porto Alegre:

\section{Bookman.}

DETERT, J. R.; TREVIÑO, L. K.; SWEITZER, V. L. (2008). Moral disengagement in ethical decision making: A study of antecedents and outcomes. Journal of Applied Psychology, 93(2), 374-391. http://dx.doi.org/10.1037/0021-9010.93.2.374

DE SORDI, J. O. (2014) Gestão por processos: uma abordagem da moderna administração. 4. Ed. - São Paulo: Saraiva.

DOLAN, P.; HALlSWORTH, M.; HALPERN, D.; KING, D.; VLAEV, I. (2010) Mindspace. London: Institute for Government, the Cabinet Office.

DOLAN, P.; HALLSWORTH, M.; HALPERN, D.; KING, D.; METCLAFE, R.; VLAEV, I. (2012) Influencing 
Maia Filho, L. F. A.; Pinho, M. A. B.

Revista Gestão.Org, v. 16, Edição Especial, 2018. p. 293-306

ISSN 1679-1827

http://www.revista.ufpe.br/gestaoorg

behaviour: The mindspace way. Journal of Economic Psychology, 33 (1), 264-277. https://doi.org/10.1016/j.joep.2011.10.009

DUMAS, M.; LA ROSA, M.; MENDLING, J.; REIJERS, H. A. (2013). Fundamentals of business process management. Heidelberg: Springer.

EIKEBROKK, T. R.; IDEN, J.; OLSEN, D. H.; OPDAHL, A. L. (2011). Understanding the determinants of business process modelling in organisations. Business Process Management Journal, 17(4), 639-662. https://doi.org/10.1108/14637151111149465

FERRIS, G. R.; BLASS, F. R.; DOUGLAS, C.; KOLODINSKY, R. W.; TREADWAY, D. C.; GREENBURG, J. (2003) Personal reputation in organizations. In: Stroh, L. K.; Northcraft, G. B.; Neale, M. A. Organizational behavior: A management challenge. Psychology Press.

FREDETTE, J.; MAROM, R.; STEINER, K.; WITTERS, L. (2012). The promise and peril of hyperconnectivity for organizations and societies. The global information technology report, 113-119. http://citeseerx.ist.psu.edu/viewdoc/download?doi=10.1.1.469.6511\&rep=rep1\&type=pdf

FROMELL, H.; NOSENZO, D.; OWENS, T. (2014). Tradeoffs between self-interest and other-regarding preferences cause willpower depletion (No. 2014-14). CeDEx Discussion Paper Series. http://hdl.handle.net/10419/129809

GALAVAN, R. J.; SUND, K. J.; HODGKINSON, G. P. (Eds.) (2017) Methodological Challenges and Advances in Managerial and Organizational Cognition. Emerald Publishing Limited.

GUISE, J. M.; WINTER, S.; FIORE, S. M.; REGENSTEINER, J. G.; NAGEL, J. (2017). Organizational and training factors that promote team science: A qualitative analysis and application of theory to the National Institutes of Health's BIRCWH career development program. Journal of clinical and translational science, 1(2), 101-107. https://doi.org/10.1017/cts.2016.17

HARRISON-BRONINSKI, K. (2014). Dealing with Human-Driven Processes. In: Broke J. V.; Rosemann, M. (eds). Handbook on Business Process Management (2). Heidelberg: Springer.

HUNT, V. D. (1996) Process mapping: how to reengineer your business processes. New York: John Wiley \& Sons.

JURISCH, M.; IKAS, C.; WOLF, P.; KRCMAR, H. (2013) Key Differences of Private and Public Sector Business Process Change. E-Service Journal, 9(1), 3-27. https://www.jstor.org/stable/10.2979/eservicej.9.1.3

KAHNEMAN, D.; EGAN, P. (2011). Thinking, fast and slow. New York: Farrar, Straus and Giroux.

LIU, C.; VLAEV, I.; FANG, C.; DENRELL, J.; CHATER, N. (2017). Strategizing with biases: making better decisions using the Mindspace approach. California Management Review, 59(3), 135-161. https://doi.org/10.1177/0008125617707973

NEAR, J. P.; MICELI, M. P. (1995) Effective-whistle blowing. Academy of management review, 20(3), 679-708. https://doi.org/10.5465/amr.1995.9508080334

OLIVEIRA, D. P. R. (2011) Sistemas, organização e métodos: uma abordagem gerencial. 20.ed. São Paulo: Atlas.

PEREIRA, L. C. B. (1996). Da administração pública burocrática à gerencial. Revista do Serviço público, 47(1), 1-28. http://repositorio.enap.gov.br/handle/1/1734

RECKER, J.; MENDLING, J. (2016) The state of the art of business process management research as published in the BPM conference. Business \& Information Systems Engineering, 58(1), 55-72. https://doi.org/10.1007/s12599-015-0411-3

SAMSON, A. (ed.) (2015) The Behavioral Economics Guide 2015. http://www.behavioraleconomics.com.

SCHAAP, M. M.; KUNST, A. E.; LEINSALU, M.; REGIDOR, E.; EKHOLM, O.; DZUROVA, D.; MACKENBACH, J. P. (2008). Effect of nation-wide tobacco control policies on smoking cessation in high and low educated groups in 18 European countries. Tobacco control, tc-2007. http://dx.doi.org/10.1136/tc.2007.024265

SCHMIEDEL, T.; BROCKE, J. V.; RECKER, J. (2015) Culture in Business Process Management: How Cultural Values Determine BPM Success. In: Brocke, J. V.; Rosemann, M. Handbook on Business Process Management. 2nd ed. 649-663. Heidelberg: Springer.

SKARLICKI, D. P.; RUPP, D. E. (2010). Dual processing and organizational justice: The role of rational versus 
Entrevista e Descoberta de Processos em Ambientes Desafiadores: uma releitura econômico-comportamental inspirada no

MINDSPACE

Revista Gestão.Org, v. 16, Edição Especial, 2018. p. 293-306

ISSN 1679-1827

http://www.revista.ufpe.br/gestaoorg

experiential processing in third-party reactions to workplace mistreatment. Journal of Applied Psychology, 95(5), 944. http://dx.doi.org/10.1037/a0020468

SILIC, M.; BACK, A. (2014) Shadow IT: A view from behind the curtain. Computers \& Security (45), 274-283. https://doi.org/10.1016/j.cose.2014.06.007

TRIPP, D. (2005) Pesquisa-ação: uma introdução metodológica. Educação e pesquisa (31)3, 443-466. http://w.scielo.br/pdf/ep/v31n3/a09v31n3

Verner, L. (2004). The challenge of process discovery. BPM Trends, May, 05-04.

WORLD BANK. (2015) World development report 2015: Mind, society, and behavior. World Bank Group. http://www.worldbank.org/en/publication/wdr2015 